\title{
The Effects of Mentor Instruction on Teaching Visual Supports to Novice, Special Education Teachers
}

\section{Samantha L. Mrstik}

Asst. Prof., Ph.D., Corresponding author, School of Education, Georgia Gwinnet College, stoneslucf@gmail.com

\section{Eleazar Vasquez}

Ph.D., Department of Child, Family, and Community Sciences, University of Central Florida

\section{Cynthia Pearl}

Ph.D., Department of Child, Family, and Community Sciences, University of Central Florida

The use of mentor teachers to sustain the longevity of a novice special education teacher is not a new tactic nor is the use of a mentor teacher's guidance in professional development for novice teachers. This study examines a new method of mentor teachers conducting professional development sessions for novice special educators through the use of short video clips, which can be viewed at the novice teachers' convenience; thus making the professional development more user-friendly and less time consuming for the busy, novice special educator. Three secondary teachers were instructed through video modelling led by a mentor teacher. The researcher used a single-subject, range changing criterion design to show the relationship between the use of mentor video instruction and the implementation of visual supports in participants' classrooms. The results of this pilot study revealed teachers improved their use of visual supports in their classrooms.

Keywords: special education, professional development, mentor teachers, visual supports, students with autism

\section{INTRODUCTION}

\section{Mentorship}

In the Teacher Follow-up Survey results from 2012-13 conducted by the National Center for Educational Statistics (2014), 8\% of teachers and 7\% of novice teachers (1-5 years of experience) left the field of education. Mentorship is one technique being used

Citation: Mrstik, S. L., Vasquez, E., \& Pearl, C. (2018). The Effects of Mentor Instruction on Teaching Visual Supports to Novice, Special Education Teachers. International Journal of Instruction, 11(1), 411-424. https://doi.org/10.12973/iji.2018.11128a 
to combat the critical problem of teacher attrition among novice teachers (Dempsey, Arthur-Kelly, \& Carty, 2009; Israel, Kamman, McCray, \& Sindelar, 2014; McLeskey \& Billingsley, 2008). Novice teachers will develop teaching habits that last throughout their careers (Billingsley et al., 2009), so districts and schools have created teacher induction programs to support novice teachers in their new careers thus preventing teacher attrition, which often include mentoring (Billingsley, Carlson, \& Klein, 2004). Mentoring has been shown to improve special education teacher retention and overall job satisfaction (Thornton, Peltier, \& Medina, 2007; White \& Mason, 2001). Mentorship in an induction program, like any professional development (PD), will need repeated meetings to be successful (Guskey \& Yoon, 2009). Online mentoring is becoming a more commonplace because it allows mentors and mentees the flexibility of meeting times and location (Dempsey et al., 2009; Israel, Carnahan, Snyder, \& Williamson, 2013).

\section{Professional Development}

The use of computer-based PD has become a routine element of teacher education. Thus online mentoring has begun to evolve. However, only a few studies have been conducted on the use of video-based mentoring being used to for PD for novice special education teachers. One study conducted by Israel et al. (2013) examined the uses of virtual coaching as a method of mentorship for novice teachers, who teach students with significant disabilities; however, the coaching model differs from the video-based methods being used in this study.

\section{Visual Supports}

Visual supports have been used to assist students with Autism Spectrum Disorder (ASD) in organization and communication (Hodgdon, 1995). Visual supports have been useful because they hold the student's attention, make abstract concepts more clear, help to reduce anxiety, and assist in communication (Rao \& Gagie, 2006). Visual supports have been listed by the National Center for Professional Development on Autism Spectrum Disorder as one of the 27 evidence-based practices successful for students with ASD (AFIRM Team, 2015). The Council for Exceptional Education (CEC) Standards supported the use of visual supports to create an effective classroom management system in Initial Preparation Standard 2: Learning Environment, ISCI 2 K1, K2, K3. Initial Preparation Standard 5: ISCI: 5 K2, calls for the use of evidence-based practices in ASD classes, and S5 states the proper sequencing of individual learning objectives, which can be obtained by the use of visual supports ("CEC standards that apply the 27 research-based practices for ASD,” 2016).

Knight, Sartini, and Sprigga (2015) conducted a comprehensive literature review of 31 articles to determine if the use of Visual Activity Schedules was an evidence-based practice for students with ASD. The authors used the five key features defined by Horner et. al. (2005) to determine the effectiveness of a study. To be considered evidence-based, a practice must have at least five studies, conducted by different researchers, in different locations, with a minimum of 20 participants over all of the studies (Horner et al., 2005). It was determined that visual supports were an evidence- 
based practice and can be used for a variety of different behaviours (Knight, Sartini, \& Spriggs, 2015).

One study examined by Knight et. al. (2015) used visual supports to facilitate transitions for students with autism. Results from this single-subject design confirmed the use of visual aids reduced the amount of time needed for transition (Dettmer, Simpson, Myles, \& Ganz, 2000).

Using an $\mathrm{ABAB}$ withdrawal treatment design, three students diagnosed with ASD were provided the methods through visual supports to learn to work independently. Independent functioning was defined as the reduction of teacher prompting and on-task behaviour. All students improved on-task behaviour and reduced the amount of prompts given by the teacher (Hume \& Odom, 2007).

Another study examined four middle school students with mild-moderate intellectual disabilities who used visual supports to manage their task completion. The visual supports were to be moved from the "to do" side of the chart to the "completed" side of the chart. Teachers prompted the student to begin the tasks. After the tasks were completed independently, a preferred snack was earned. Using a withdrawal design, researchers determined all four students had been successful in managing tasks independently with the use of visual supports (Duttlinger, Ayres, Bevill-Davis, \& Douglas, 2013).

\section{Purpose}

The purpose of this study is to determine the extent of which video-based, mentor-led instruction for novice teachers in a secondary, Varying Exceptionalities, self-contained classroom, can increase teacher use of visual supports. The questions to be answered by this study are, (1) To what extent, does the Mentor Demonstration Classroom (MDC) teacher lead video modelling with feedback increase the percentage of the use of classroom use of visual support as measured by an adapted visual support checklist for a secondary, special education teacher in a secondary, self-contained, Varying Exceptionalities classroom?, and (2) To what extent, do participants feel PD through use of video, taught by a classroom teacher is a valuable resource, as measured by survey? This study will add to the limited research on video-based mentorship.

\section{METHOD}

\section{Participants and setting}

Project ASD (Autism Spectrum Disorder) is a grant-funded program for teachers to obtain a M.Ed. or a M.A. in the area of teaching students with ASD at a large southeastern university in the United States. A component of Project ASD is the Mentor Demonstration Classroom (MDC). The purpose of the MDC is to provide masters-level students taking classes in Project ASD a quality classroom observation with teachers who are using evidence-based practices. The MDC teacher has been identified as exemplary in district teacher evaluations and in multiple observations by project staff using the Project Observation Assessment for Teachers Providing Services to Students with ASD (see Appendix A). 
Participants in this study were masters-level students, who were also working teachers. The participants were selected through a purposive sample (Gall, Gall, \& Borg, 2007). Three participants were chosen who worked in a public, urban or suburban, high school or middle school, self-contained unit for students with ASD, Intellectual Disabilities (ID), or a Varying Exceptionalities (VE) classroom in three districts. Horner et. al. (2005) wrote, "External validity of results from single-subject research is enhanced through replication of the effects across different participants, conditions and measures of the dependent variable." (p.174). Thus to increase the external validity, this study was replicated over three participants. Subjects were chosen using the following criteria: new to the field of special education (within the teachers' first 5 years), assigned to a secondary school (grades 6-12), assigned to a self-contained classroom serving students with ASD, ID, or VE, and scored a zero or one on each level of the Evidence-Based Practices Checklist for Secondary (see Appendix A) during baseline. Participants were recruited from a masters-level course in teaching students with ASD.

Participant one was a high school teacher with a self-contained, varying exceptionalities class within a large, urban high school. Participant one had seven students and two assistants in the classroom. All students had been diagnosed with ASD or an Intellectual Disability (ID). The academic levels of the students in the class ranged from nonverbal to verbal, basic readers (grades K-3). Participant one had five years of teaching experience and four years of paraprofessional experience prior to becoming a teacher.

Participant two was a middle school teacher with a self-contained, VE class within a large, suburban middle school. Participant two a classroom of had four students and one assistant in the classroom. All students had been diagnosed with ASD or ID and were able to read, write, and are verbal. Participant two had five years of teaching experience and was an Applied Behavioural Analyst prior to teaching.

Participant three was a high school teacher who had five students and two assistants. The school was a large suburban high school, and the class was a self-contained unit for students with ASD. Four students were categorized as ASD and one student was categorized as ID. Three of these students were verbal and are able to read at a basic level (K-3). The other students in class were nonverbal. Participant three had taught for four years.

\section{Independent variable}

The researcher chose a secondary, MDC teacher who was proficient in the use of visual supports in the classroom. The teacher had been identified as exemplary on her district evaluation and on the evaluation tool used for master program in ASD, which aligns with CEC standards, including the use of visual supports. The MDC teacher chosen to conduct the PD was a secondary teacher and was willing to instruct by video using her classroom and materials.

The researcher created four videos using an iPad. Each video was under five minutes in length. A different type of visual support was selected for each video and coincided with the Visual Supports Checklist (see Table 1). The setting of the video instruction 
was MDC teacher's classroom, and the MDC teacher provided instruction, using examples from their secondary classroom.

Table 1

Visual Supports Criterion

\begin{tabular}{ll} 
Visual Supports & Operational Definitions of Visual Support \\
\hline VS 1 & $\begin{array}{l}\text { Task organizers- picture, word, or picture and word labels to provide } \\
\text { students with step-by-step instructions of daily activities (e.g. going to the } \\
\text { bathroom, washing hands) }\end{array}$ \\
\hline VS 2 & $\begin{array}{l}\text { Label classroom areas- picture, word, or picture and word labels to provide } \\
\text { students names of class areas (e.g. bathroom, computer area) }\end{array}$ \\
\hline VS 3 & $\begin{array}{l}\text { Choice Board- picture, word, or picture and word labels to provide students } \\
\text { options of what they wish to do when they earn their free time (e.g. } \\
\text { computer time, music time) }\end{array}$ \\
\hline VS 4 & $\begin{array}{l}\text { Class Schedule- picture, word, or picture and word labels to provide } \\
\text { students a daily class schedule of activities in the order they will occur (e.g. } \\
\text { Period 1- electives, Period 2- small group math and reading rotations) }\end{array}$ \\
\hline
\end{tabular}

The videos were opened online over the duration of a week. Participants were provided with a viewing link via email. After the teacher participants viewed the view, they selected an observation time with the use of a Doodle Poll. The evaluator observed in each teacher participants' classroom and provided feedback on the use of the visual supports being used during the observation.

The evaluator conducting the observation must be able to identify and discuss evidencebased practices for students with ASD and ID in a secondary setting. The evaluator should have experience working in a self-contained classroom.

\section{Fidelity of Implementation}

The researcher controlled fidelity of implementation by the release of videos in increments. All participants viewed the same videos during the same window of time. The researcher was able to view when the participants had watched the videos

\section{Dependent Variable and Measurement}

The Evidence-Based Practices Checklist for Secondary (see Appendix A) was adapted from the Visual Supports Checklist (Bennett-Armistead, Blagojevic, Neal, \& Taylor, 2011). The Visual Supports Checklist was developed to assess a teacher's use of visual supports to assist in a students' ability to find where an item belongs, understand a schedule, understand directions, interact with others, and understand how to communicate thought or choices (Bennett-Armistead et al., 2011). The researcher adapted this tool to make it more appropriate for secondary classrooms, and rather than the scale of Already Using and Not Using Yet, the measure was changed to a numeric scale to allow for differing degrees of use in a classroom (see Table 2). 
Table 2

Scale used to evaluate the use of visual supports

\begin{tabular}{ll}
\hline Measurement & Criteria for Score \\
\hline 3 & $\begin{array}{l}\text { VS is in the classroom is present, high quality, age appropriate, durable, and } \\
\text { the teachers, asst., or students used consistently. }\end{array}$ \\
\hline 2 & VS is present but not consistently used or somewhat achieved. \\
\hline 1 & $\begin{array}{l}\text { VS is present in the classroom, but is not used or implemented by the } \\
\text { teacher, asst. or students; or it is minimally achieved (one or more of the } \\
\text { following: poor quality, not age appropriate, lacks durability, or mislabelled } \\
\text { visual representation). }\end{array}$ \\
\hline 0 & Not present in classroom
\end{tabular}

The researcher used the Evidence-Based Practices Checklist for Secondary to evaluate the teachers' use of visual supports in the classroom. All observations were taken in increments of 20 minutes over 9 class visits. The time of day the observations took place varied over a period of 11 weeks.

The Evidence-Based Practices Checklist for Secondary (see Appendix A) was shared with the teachers prior to the first observation. After each observation, the researcher provided feedback to the participants on their use of the visual support being assessed during observations.

Interrater reliability was conducted by member of the research team, who attended and rated $7 \%$ of the observations with a $96 \%$ agreement. All observations not attended by a second member of the research team were recorded using an iPad, and reviewed by the researcher.

\section{Procedures}

Baseline was taken in each participant's classrooms to evaluate the usage of visual supports. Data taken during baseline was used to compare performance after the intervention was administered (Horner et al., 2005). Five baseline observations were conducted over two visits to the participants' classrooms. The duration of each observation was in twenty-minute increments. Participants who scored a level zero or one during baseline met the criteria to continue the intervention.

After baseline, the researcher uploaded each of the four MDC visual supports videos to Adobe Connect (Adobe Connect, 2016), and only one video was distributed at a time. Participants were emailed a link to view the video and given a window of time the video would be available for viewing. The participants were also emailed a link to a Doodle Poll to schedule a researcher observation. The researcher used the Evidence-Based Practices Checklist for Secondary (see Appendix A) during observations. Participants who scored a level two or three were able to move to the criterion (see Table 1).

The researcher set the criterion range at a score of a level two or three on the EvidenceBased Practices Checklist for Secondary. This decision was made to preserve the organic routine and structure of the classroom, rather than the participant feeling teacher participants must use multiple visual supports during an observation. The use of all four types of supports during an observation period may have been confusing to students 
because it would be an unnatural part of the student's routine. Only one visual support criterion was introduced and measured during observation.

Each of the four criterions was worth $25 \%$ of $100 \%$. Once a criterion was mastered at a level two or three (see Table 3), the percentage was calculated and recorded. The next criterion was released, and the observer used the Evidence-Based Practices Checklist for Secondary to measure the coinciding practice. Again, the practice was calculated into a percentage, added to the former score, and recorded. The process continued for all four criterions.

Table 3

Experimental Procedures

\begin{tabular}{|c|c|}
\hline Procedures & Details of each Procedural Step \\
\hline \multirow[t]{2}{*}{ Baseline } & 1. Take until stable \\
\hline & 2. Minimum of five observations \\
\hline \multirow[t]{3}{*}{ VS 1} & 1. VS 1 Video \\
\hline & 2. Observation to evaluate the use of VS 1 in the classroom \\
\hline & 3. Researcher feedback \\
\hline \multirow[t]{3}{*}{ VS 2} & 1. VS 2 Video \\
\hline & 2. Observation to evaluate the use of VS 2 in the classroom \\
\hline & 3. Researcher feedback \\
\hline \multirow[t]{3}{*}{ VS 3} & 1. VS 3 Video \\
\hline & 2. Observation to evaluate the use of VS 3 in the classroom \\
\hline & 3. Researcher feedback \\
\hline \multirow[t]{3}{*}{ VS 4} & 1. VS 4 Video \\
\hline & 2. Observation to evaluate the use of VS 4 in the classroom \\
\hline & 3. Researcher feedback \\
\hline
\end{tabular}

\section{Experimental design}

A classic changing criterion design administers the independent variable in steps with the goal of behaviour change in an accelerating or decelerating fashion (Klein, Houlihan, Vincent, \& Panahon, 2015; McDougall, Hawkins, Brady, \& Jenkins, 2006). A changing criterion design must have a treatment period long enough for the treatment to re-stabilize (Gast \& Ledford, 2014, p. 347; Hartmann \& Hall, 1976).

After the video-viewing window closed, participants were given approximately a week and a half before the next observation, except during spring break, when they were given two and a half weeks. The time in between each video allowed teacher participants time for preparation of the visual support and time to begin implementation of the visual support with their students. The researcher permitted the participants to choose when they wanted to their observations after each video was viewed.

Hartman and Hall (1976) suggested two or more criterions. Four criterions were used for this study. A classic changing criterion design typically chooses one behaviour or academic area and increases in difficulty with each criterion (Schloss, 1982). Rather than increasing in difficulty, this study introduced a new skill with each criterion. A changing criterion design is suitable for wide range teaching in small increments (Hartmann \& Hall, 1976), for shaping procedures (Hartmann \& Hall, 1976), and gradual increase in performance (Schloss, 1982). 
A range changing criterion design was used for this study. A range changing criterion design is similar to a classic criterion design, but the range criterion design uses an upper and a lower criterion rather than only a single performance point (McDougall et al., 2006).

\section{FINDINGS}

To answer the first research question, "To what extent does the Mentor Demonstration Classroom (MDC) teacher lead video modelling with feedback increase the percentage of the use of classroom use of visual support as measured by an adapted visual support checklist for a secondary, special education teacher in a secondary, self-contained, Varying Exceptionalities classroom?" each participant was provided baseline, four video-mentoring sessions, and four observations with feedback. Results are discussed for each participant individually.

The range of acceptable performance was a level 2 or 3 on the Evidence-Based Practices Checklist for Secondary in each criterion area. The upper line on the graph for each criterion indicates the highest a participant is able to score. The lower line represents the lowest a participant can score in this criterion. The range for VS 1 is 16.6 to 25 . The range for VS 2 is 33.24050 . The range for VS 3 is 49.8 to 75 . The range for VS 4 is 66.4 to 100 . If a participant scored all level 2 in every criterion, the end result would total 66.4.

Participant One's (P1) baseline was steady throughout the five observations. P1 did have a class schedule (VS 4) posted but did not refer to the schedule or use the schedule throughout the duration of baseline. P1 had labels (VS 2) in the classroom, but not all areas were labelled correctly. Labels were sporadic and inconsistent, but the labels were high quality. P1 scored a level 3 on each of the criterion (see Table 4). All of the visual supports P1 employed were high quality, durable, and used in the manner in which they were designed (see Table 4).

\section{Table 4}

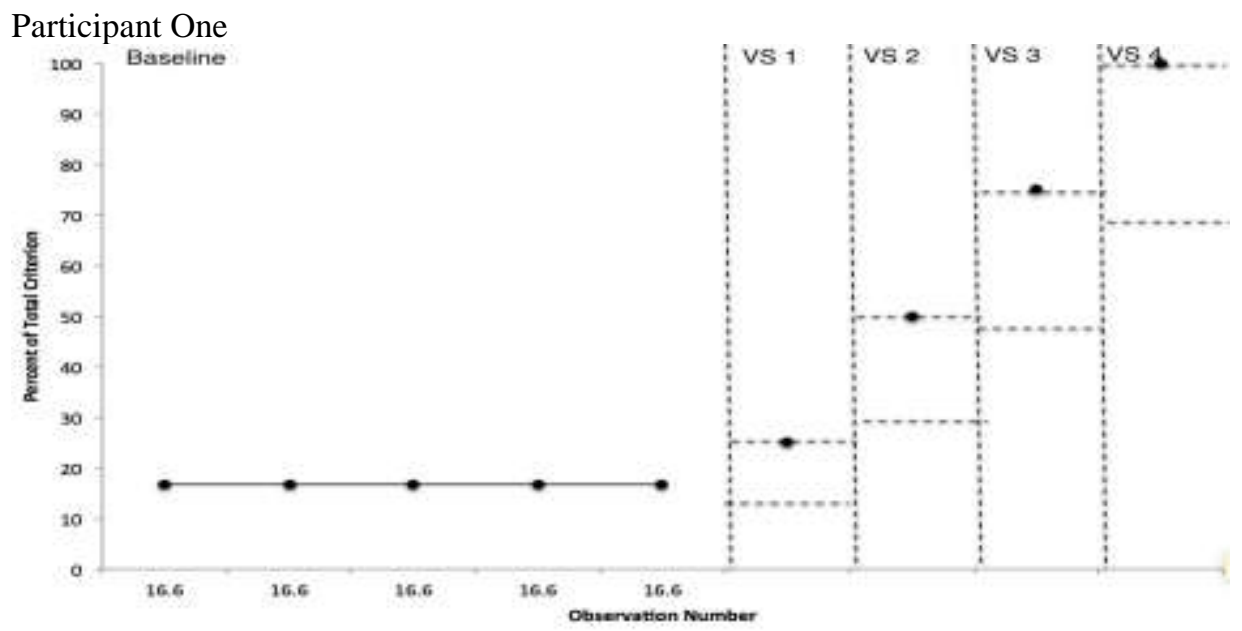


Participant two (P2) was steady throughout baseline, with the exception of baseline observation three when $\mathrm{P} 2$ had a class schedule on the whiteboard. P2 used labels in the class, but the labels were inconsonantly placed and not used or referred to by the teacher or the assistant. After viewing the first video in the series, Task Organizers, P2 had placed a high quality, task organizer in the student bathroom describing the steps to hand washing. The task organizer was in full sentences with corresponding pictures, which is appropriate for the age and level of the students in the classroom, however, P2 did not use the task organizer during the observation. P2 scored a 2 according to the assigned criteria. Similarly, P2 did have class labels (VS 2) written in words over key areas of the classroom but did not refer to or use any of the labels during observation 2 . During observation 3 and 4, P2 scored a 3. P2 used choice boards (VS 3) with a student to earn free time, and P2 employed the use of individual and whole class schedules (VS 4). P2 had a total score of 83.2 when combining all areas (see Table 5).

Table 5

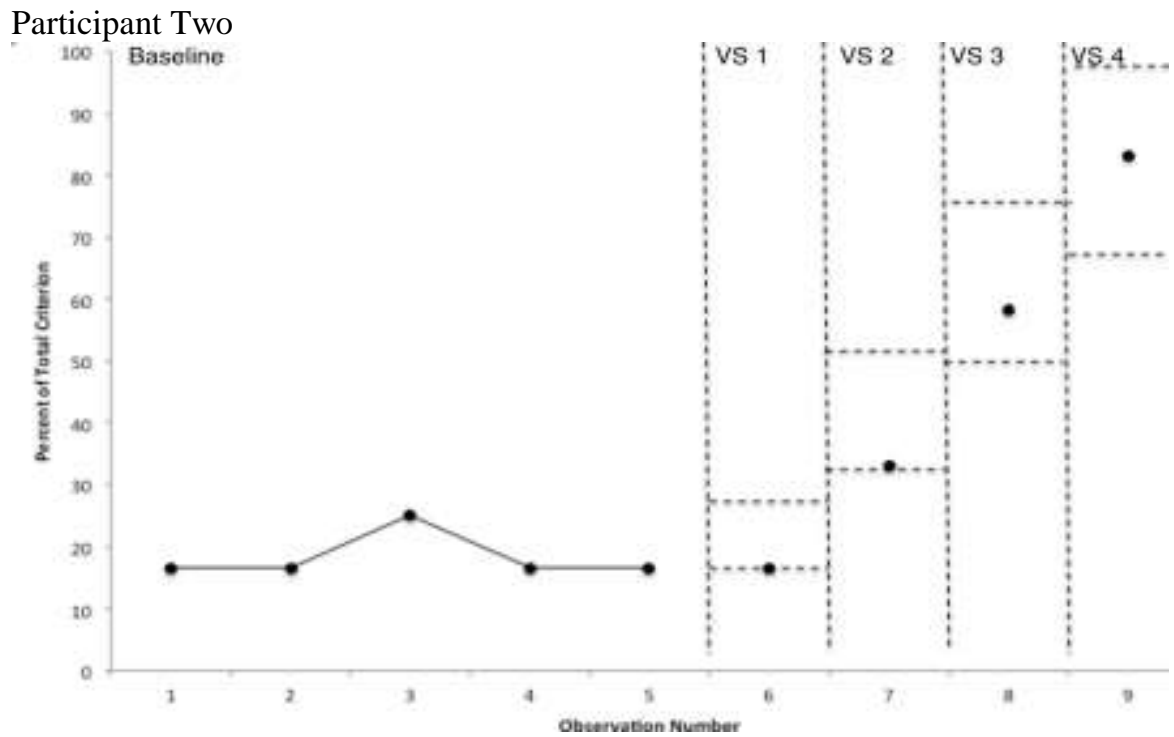

Participant three (P3) was steady throughout baseline observations. P3 had minimal visual supports in the classroom. After viewing the video on task organizers, P3 implemented a high quality, premade task organizer with pictures with one student in the class. During the observation, P3 was teaching the use of the task organizer to the student, however the task organizer was not age appropriate for the student, so VS1 was rated as a level 2. Although P3 only implemented the task organizer with one student, the rating scale did not specify the whole class use or a specific amount of students using the visual support. P3 labelled the major areas of the classroom (i.e., computer, door, student) after watching the VS 3 video, but the labels were poor quality and not durable. P3 and the classroom assistants referred to and used the labels during instruction, so P3 was rated a level 2. During the observation evaluating VS 3, P3 used a choice board with one student to earn free time. P3 scored a level 2 due to the criteria not specifying 
the amount of students being impacted by the visual support. P3 referred to a schoolwide, whole class, bell schedule, and P3 and the class assistants developed and implemented an individual schedule for one student during the observation evaluating VS 4. The whole class bell schedule was in every classroom in the high school, and it was all in text format. Most students in the class were unable to read, and although it was age appropriate, it was not useful in this class. The individual schedule implemented was a high quality, premade visual support. The schedule was all pictures with no text provided. The student using the schedule was able to read, so the individual schedule was not appropriate. The teacher and assistants used the schedules in class, but they were not appropriate for the specific needs of the classroom or students. P3 scored a level two for VS 4. When combining all of the score, PS 4 scored a total of 66.4 (see Table 6).

\section{Table 6}

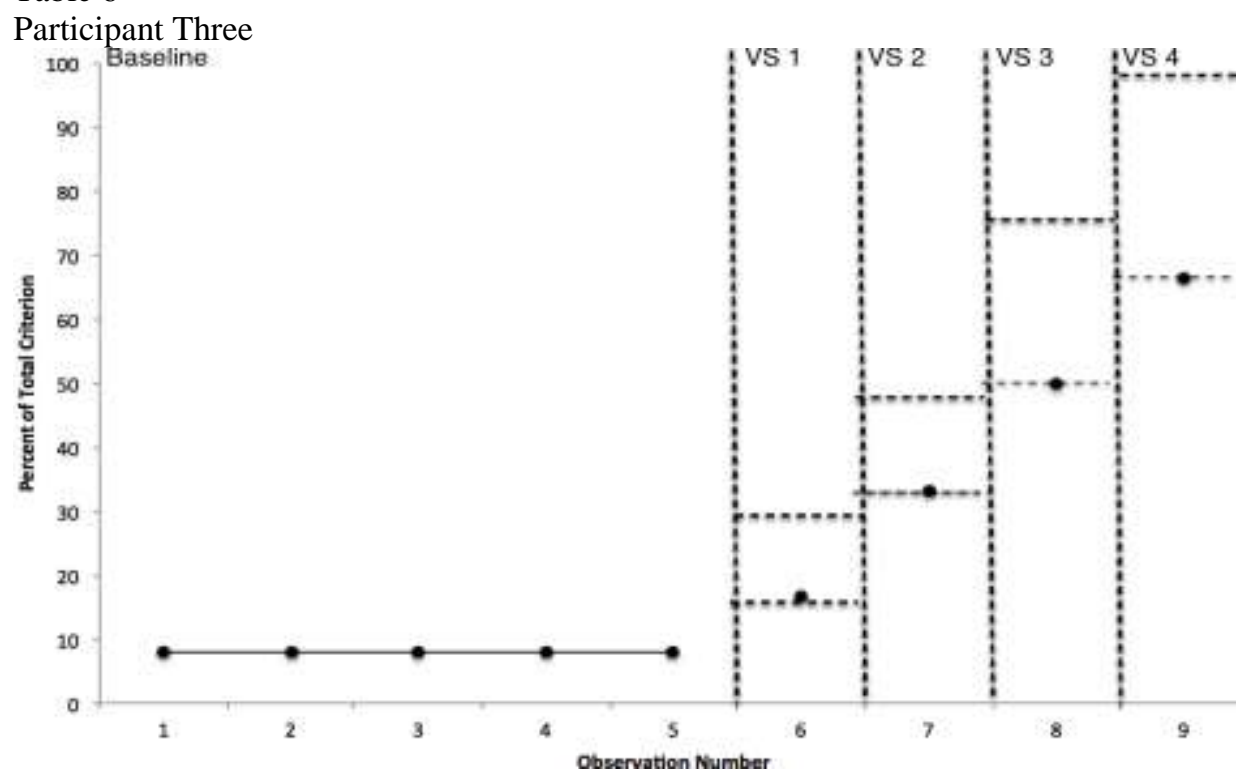

\section{Social Validity}

Social validity is defined as the social significance of goals, procedures, and effects of research (Wolfe, 1978). To answer the research question, "To what extent do participants feel PD through use of video, taught by a classroom teacher, is a valuable resource, as measured by survey." A 6 question survey was administered through the use of Qualtrics (Qualtrics, 2016). All participants responded to the survey. Two participants strongly agreed and one agreed the use of short video clips made it convenient to learn about visual supports (see Table 4). All three participants strongly agreed with the use of a classroom teacher as the instructors of the video series (see Table 7). Two participants were extremely satisfied, and one was moderately satisfied in the overall video instruction. 
Table 7

Summary of Social Validity

\begin{tabular}{lll}
\hline Questions & $\begin{array}{l}\text { Number of participants } \\
\text { to answer agree }\end{array}$ & $\begin{array}{l}\text { Number of participants to } \\
\text { answer strongly agree }\end{array}$ \\
\hline $\begin{array}{l}\text { Do you feel the use of the short video } \\
\text { clips made it convenient for you to learn } \\
\text { about visual supports? }\end{array}$ & 2 \\
\hline $\begin{array}{l}\text { Do you feel using a classroom teacher for } \\
\text { the instruction videos was beneficial? }\end{array}$ & 0 & 3 \\
$\begin{array}{l}\text { Please rate your overall satisfaction of the } \\
\text { video instruction. }\end{array}$ & 1 & 2 \\
\hline
\end{tabular}

\section{Limitations}

The participants in this study were all teachers and master-level students. Most teachers and masters-level students are, by nature, good students and strive to make good grades. Because participants were observed only four times outside of baseline, the Hawthorne Effect could explain the rapid change in participant behaviour. The participants may have only used the visual supports during the observation to appease the observer.

The researcher did not secure 30\% inter-rater reliably for this study. However $7 \%$ interrater reliability was obtained. When developing the rating scale to be used on the Evidence-Based Practices Checklist for Secondary, it was not specified as to how many students were impacted by the visual support. The rating scale also needed to define more specifically the term "age appropriate".

\section{DISCUSSION}

Visual supports are one of the 27 evidence-based practices recommended by The National Center of Autism (AFIRM Team, 2015) and are aligned with the CEC standards ("CEC standards," 2016). All participants improved their use of the four visual supports discussed in the video series. Data was analysed using visual analysis. Visual analysis is the interpretation of the level, trend, and variability during each phase of the study (Horner et al., 2005).

Even though all of the participants improved their use of visual supports, several challenges persisted in this study. Due to the disparity in the level of functioning of the students in the participants' classes, the use of visual supports varied greatly to accommodate student need. While all three participants progressed in their use of visual supports in the classroom, they did not progress equally. Some participants needed to create visual supports for their students, while others already had visual supports created. This presented a problem for the participants who needed to invest time in the production of visual supports because the visual support was of lower quality.

Israel et al. (2013) examined the use of virtual coaching for novice special education teacher. It was the researcher's objective to create a PD and mentoring combination, which would not be time-consuming and could be used at the novice teachers' convince. This video-based, mentoring technique was instructed by an experienced, mentor teacher in the mentor teacher's classroom, rather than a researcher. The social validity 
survey provided verification of the convenience, use of time, and overall satisfaction (see Table 5).

In this pilot study, researchers found small increments of mentorship through videoinstruction improved the use of visual supports in secondary, self-contained classroom for students with intellectual disabilities and ASD. More research should be completed in this area using other evidence-based practices for students with ASD, longer, more involved videos, and prolonged observation time period.

\section{REFERENCES}

Adobe Connect (2016). Adobe systems incorporated.

AFIRM Team. (2015). Visual supports. Retrieved from http://autismpdc.fpg.unc.edu/evidence-based-practices

Bennett-Armistead, S., Blagojevic, B., Neal, E., \& Taylor, B. (2011). Visual Supports Checklist. University of Maine.

Billingsley, B., Carlson, E., \& Klein, S. (2004). The working conditions and induction support of early career special educators. Exceptional Children, 70(3), 333-347.

Billingsley, B., Griffin, C., Smith, S., Kamman, M., Israel, M., \& National Center to Inform Policy and Practice in Special Education Professional Development (NCIPP). (2009). A review of teacher induction in special education: Research, practice, and technology solutions (No. RS-1ES). University of Florida: National Center to Inform Policy and Practice in Special Education Professional Development.

$\begin{array}{llll}\text { CEC standards. } & \text { (2016). Retrieved from }\end{array}$ http://afirm.fpg.unc.edu/sites/afirm.fpg.unc.edu/files/imce/resources/CEC\%20Standards. pdf

Dempsey, I., Arthur-Kelly, M., \& Carty, B. (2009). Mentoring early career special education teachers. Australian Journal of Education, 53(3), 294-305.

Dettmer, S., Simpson, R. L., Myles, B. S., \& Ganz, J. B. (2000). The use of visual supports to facilitate transitions of students with autism. Focus on Autism \& Other Developmental Disabilities, 15(3), 163-169.

Duttlinger, C., Ayres, K. M., Bevill-Davis, A., \& Douglas, K. H. (2013). The effects of a picture activity schedule for students with Intellectual Disability to complete a sequence of tasks following verbal directions. Focus on Autism \& Other Developmental Disabilities, 28(1), 32-43. https://doi.org/10.1177/1088357612460572

Fishman, B., Konstantopoulos, S., Kubitskey, B. W., Vath, R., Park, G., Johnson, H., \& Edelson, D. C. (2013). Comparing the impact of online and face-to-face professional development in the context of curriculum implementation. Journal of Teacher Education, 64(5), 426-438. https://doi.org/10.1177/0022487113494413

Gall, M., Gall, J., \& Borg, W. (2007). Educational research (8th ed.). Boston: Pearson. 
Gast, D., \& Ledford, J. (2014). Single case research methodology. New York: Routledge.

Guskey, T., \& Yoon, K. S. (2009). What works in professional development? Phi Delta Kappan, 90(7), 495-500.

Hartmann, D. P., \& Hall, R. V. (1976). The changing criterion design. Journal of Applied Behavior Analysis, 9(4), 527-532. https://doi.org/10.1901/jaba.1976.9-527

Hodgdon, L. (1995). Solving social-behavioral problems through the use of visually supported communication. In Teaching children with autism: Strategies to enhance communication and socialization (pp. 265-286). Albany, N.Y.: Delmar Publishers, 1995.

Horner, R. H., Carr, E. G., Halle, J., McGee, G., Odom, S., \& Wolery, M. (2005). The use of single-subject design research to identify evidence-based practice in special education. Exceptional Children, 71(2), 165-179.

Hume K., \& Odom, S. (2007). Effects of an individual work system on the independent functioning of students with autism. Journal of Autism \& Developmental Disorders, 37(6), 1166-1180.

Israel, M., Carnahan, C. R., Snyder, K. K., \& Williamson, P. (2013). Supporting new teachers of students with significant disabilities through virtual coaching a proposed model. Remedial and Special Education, 34(4), 195-204. https://doi.org/10.1177/0741932512450517

Israel, M., Kamman, M. L., McCray, E. D., \& Sindelar, P. T. (2014). Mentoring in action: The interplay among professional assistance, emotional support, and evaluation. Exceptional Children, (1), 45-63.

Klein, L., Houlihan, D., Vincent, J., \& Panahon, C. (2015). Best practices in utilizing the changing criterion design. Behavioral Analysis Practice.

Knight, V., Sartini, E., \& Spriggs, A. (2015). Evaluating visual activity schedules as evidence-based practice for individuals with autism spectrum disorders. Journal of Autism \& Developmental Disorders, 45(1), 157-178. https://doi.org/10.1007/s10803014-2201-z

McDougall, D., Hawkins, J., Brady, M., \& Jenkins, A. (2006). Recent innovations in the changing criterion design: Implications for research and practice in special education. Journal of Special Education, 40(1), 2-15.

McLeskey, J., \& Billingsley, B. S. (2008). How does the quality and stability of the teaching force influence the research-to-practice gap? A perspective on the teacher shortage in special education. Remedial and Special Education, 29(5), 293-305. https://doi.org/10.1177/0741932507312010

Qualtrics. (2016). (Version 2016). Provo, Utah: Qualtrics. 
Rao, S. M., \& Gagie, B. (2006). Learning through seeing and doing: Visual supports for children with autism. Teaching Exceptional Children, 38(6), 26-33.

Schloss, P. J. (1982). Application of the changing-criterion design in special education. Journal of Special Education, 16, 359-367.

Thornton, B., Peltier, G., \& Medina, R. (2007). Reducing the special education teacher shortage. Clearing House, 80(5), 233-238. https://doi.org/10.3200/TCHS.80.5.233-238

White, M., \& Mason, C. (2001). The mentoring induction project "What new teachers need from mentors?" Exceptional Children, 33(6), 81-82.

Wolfe, M. (1978). Social validity: The case for subjective measure or how applied behavior analysis is finding its heart. Journal of Applied Behavior Analysis, 11(2), 203214.

\section{Appendix A}

\begin{tabular}{ll}
\hline Demographic information & Circle the session and provide the session number \\
\hline Teacher's Name & Baseline \\
School & VS 1 \\
Date & VS 2 \\
Time & VS 3 \\
& VS 4 \\
\hline
\end{tabular}

Evidence-Based Practice Checklist for Secondary, Varying Exceptionalities Classrooms

Instructions for use: Please fill out the evaluation form by checking the box using the following criteria.

3- VS is in the classroom is present, high quality, age appropriate, durable, and the teachers, asst., or students use consistently.

2- VS is present but not consistently used or somewhat achieved.

1 - VS is present in the classroom, but is not used or implemented by the teacher, asst. or students; or it is minimally achieved (on or more of the following: poor quality, not age appropriate, lacks durability, or mislabelled visual representation).

0 - not present in classroom 